\title{
Can a Week Make a Difference? Changing Perceptions about Teaching and Living in Rural Alaska
}

\author{
T. R. Munsch \\ Alaska Pacific University \\ Colin R. Boylan \\ Charles Stuart University
}

\begin{abstract}
Many Alaskan schools are located in extremely remote or 'fly-in' places. These geographical extremes affect the recruitment and retention of teachers to remote rural schools. Through a partnership between the Southwest Region School District of Alaska and the Department of Education at Alaska Pacific University (APU), 14 pre-service teachers participated in a one-week remote rural practice teaching experience. These APU students lived and taught in village schools where indigenous Alaska Natives were the majority and whose language is Yup'ik. Through the use of pre and post experience questionnaires, the pre-service teachers' views about rural teaching and seeking rural appointments were sought.
\end{abstract}

\section{Introduction}

The challenging issues of teacher recruitment and retention in many western countries including the USA, Canada, and Australia have been identified as priority concerns by federal, state and provincial education departments (Collins, 1999; Human Rights and Equal Opportunity Commission, HREOC, 2000; Jimerson, 2005; Lowe, 2006). Additionally, there is a body of literature that has clearly identified teacher shortages at the secondary level as critical especially in these areas of specialization: Agriculture, Computer Studies, English, Mathematics, Science, and Technology Studies. This situation has been discussed by AEU (2001), Hardy (1998), HREOC (2000), Kirby, Berends and Naftel (1999), Lemke and Harrison (2002), Nichols (2004), and Williams (2002). Further, in some American states, an emerging shortage of elementary teachers has also been identified. For example in Alaska approximately 250 pre-service teachers graduate each year while collectively, Alaskan school districts need about 1100 teachers to replace teachers who retire or leave the Alaskan system. Staffing shortages are not unique to the Alaskan education system. For example, the New South Wales education system in Australia is currently experiencing similar staffing shortages, especially for its rural, remote and hard-to-staff schools. With over half of all 2200 New South Wales schools located in rural and remote areas, the NSW Department of Education and Training has established recruitment strategies that promote the benefits of a rural appointment to the city bred and trained per-service teachers. One such strategy targeting pre-service teacher trainees is a program called 'Beyond the Line' which is similar in design to the APU program in which students spend a week in rural and remote NSW schools (New South Wales Department of Education and Training, NSWDET, 2001). Coupled with this significant teacher recruitment challenge, Alaska is geographically the largest state yet is one of the more sparsely populated states. Alaska's population was approximately 649,000 people in 2004 with Anchorage's population being estimated at 271,000 (United States Census Bureau, 2000). Rural Alaskan villages are classified as either on the road system or "bush" communities, reachable by boat or plane (or snow machine in the winter months). The State of Alaska provides a definition:

The vast majority of Alaska not connected to the existing road system - the Bush is a hugely different thing. Technically, demographers don't really have a word that adequately describes our diverse and scattered collection of over 250 small villages, towns and remote outposts. Alaska Statutes define "rural" as meaning a community with a population of 5500 or less, and not connected by road or rail to Anchorage or Fairbanks, or with a population of 1,500 or less and still connected by road or rail. (State of Alaska, n.d.)

According to the web site of the Alaska Teacher Placement online information section accessed in 2006:

The vast majority of the state of Alaska meets this definition. There are other definitions. Just like rural Australia, and parts of Africa, the remote places in Alaska are collectively referred to as "the Bush". In a study a few years ago, about $64 \%$ of Alaska's districts, $53 \%$ of its schools, and $40 \%$ of its population are located "in the Bush" (NWREL, 1999). Village residents are pretty comfortable in their world, and skilled at living there. You will not be at first, so just accept that learning curve (Alaska Teacher Placement, 2006, no page number). 
Boylan (2005), Boylan, Squires and Smith (1994), Munsch and Boylan (2005), Murphy and Cross (1990), Ralph (2002), and Yarrow, Herschell and Millwater (1999) are among many authors who have focused attention on the specialized needs for rural service and on the specific preservice preparation requirements necessary to address rural teaching challenges.

Gibson (1994) and Halsey (2005) have further clarified the specialized needs and both authors agree that one significant recruitment strategy in pre-service teacher education programs is the inclusion of, at least, one practice teaching experience where their students experience teaching and living in rural and remote locations. Halsey (2005) suggested that such experiences should evolve as cooperative partnerships between the university, the rural school and the community. It is argued that the current study of such a partnership program between Alaska Pacific University and remote Native Alaskan villages and their schools meets the recommendations made by Gibson (1994) and Halsey (2005). Allen (2003) reviewed the empirically based literature exclusively form the United States of America that examined the issue of rural pre-service teacher education. Allen (2003) concluded by identifying the need to provide rural practice teaching experiences and training in multi-cultural awareness as essential components for all rural pre-service preparatory programs.

Boylan and Hemmings (1992), HREOC (2000) and Ralph (2003) reported that a period of practice teaching in rural and remote schools in Australia and Canada had a significant effect on changing pre-service teacher's views on seeking and/or accepting a rural appointment. Similar findings have been reported by Yarrow, Ballantyre, Hansford, Herschell and Millwater (1998) in Queensland, Australia. The practice has been suggested by Jimerson (2005) in her report to the Center on Educational Policy on potentially effective recruitment strategies. One problem with such programs is that some students for financial, familial, or employment related reasons are unable to participate in these rural practice teaching experiences.

\section{Teacher Shortages in Alaska}

The recruitment of teachers for rural and remote schools is a challenging task that all school systems experience and this challenge is increased during times of teacher shortages (Collins, 1999; Nichols, 2004). Alaskan rural school district administrators have identified a priority staffing program in which the recruitment of prospective pre-service students and qualified teachers to rural and remote Alaskan school districts is actively pursued at both the district and state level. As noted by Jordan and Jordan (2004), Alaska is classified a rural state no matter what classification system is used. Factors contributing to the difficulty in rural staffing in general have been described by Jimerson (2005): a preexisting teacher shortage, comparatively low salaries, high incidence of multiple-subject teaching assignments, and actual or perceived social, cultural and professional isolation.

\section{Rural Pre-service Teacher Education}

Sharplin (2002) explored the barriers that city-based preservice teacher education students perceive as limiting their acceptance of a rural / remote teaching appointment. In her study of 22 Australian secondary pre-service teachers, she reported that only one student had lived in remote Western Australian location. Her research revealed that students held multiple perceptions about the professional challenges of rural and remote appointments that included: a) a lack of teaching resources (55\%); b) limited access to a support network of experienced teachers (36\%); and, c) a lack of familiarity with school students' cultural background, language and socio-economic status (36\%). These challenges were uppermost in the minds of these students. She probed their perceptions further and identified that many pre-service teachers held personal and social perceptions that dwelt on uncertainty about: a) how to relate to and adjust to life in small rural communities (59\%); b) isolation from family and friends (36\%); and, c) concerns about establishing new support networks (36\%). Sharplin (2002) found that six students (27\%) were prepared to accept a rural appointment but for less than two years. She argued that much of the students' ideas about rural placement were based on negative and idealized preconceptions about rural teaching and lifestyle issues, which reduced the likelihood of accepting a rural appointment. Sharplin (2002) concluded by urging more teacher education programs to consider the inclusion of rural and remote experiences as part of their pre-service program. This was sentiment also identified by Lock (2007), Boylan (2005), Halsey (2005), and Ralph (2002). The Alaska Pacific University's Remote Rural Practicum program is one innovative model of how this challenge can be met within the teacher education program that prepares prospective teachers for appointments to remote Alaska villages.

By contrast to the above research which focused on what should be or what it might be like, a study by Lock (2007) of urban based pre-service teachers in Western Australia who had participated in the Student Teacher Rural Experience Program (STREP) examined the effect of their participation in a rural practice teaching experience on the decision to seek a rural teaching appointment. He reported that 22 respondents (73\%) indicated that participation in the program encouraged them to apply for rural/remote teaching appointments. Additionally through their participation in STREP, these urban-based students reported they developed a better understanding about staff and community relationships in rural places. Lock's study is aligned closely to other research by Boylan and Wallace (2002) and Munsch and Boylan (2005) in which students who were provided with rural teaching experiences as part of their pre- 
service teacher education programs reported: a) better understandings about the context of rural teaching; and, b) a greater preparedness to seek a rural appointment upon graduation.

Since 1995, staff of the Education Department at Alaska Pacific University sought opportunities to place pre-service teachers in rural settings to experience the challenges faced by teachers in those schools. Because all on-campus students in the undergraduate Bachelor of Arts Teacher Preparation Program (TPP) and the Master of Arts in Teaching program (MAT) reside in Anchorage during their educational pursuits, a priority for the practicum program has been to provide an opportunity to experience first hand teaching and living in a rural village. Alaskan rural schools often pay much higher starting salaries than do urban school districts (the opposite of salary disparities in other rural states), hence newly certified teachers are wont to "follow the money" and often consider taking a rural position in their first year of teaching. Those new teachers who have participated in rural practicum experiences, we believe, know more about what to expect during their first year of teaching in a rural school and living in a rural community than those who have not been there or not done that. In recognition of these acute recruiting needs, Alaska Pacific University, which is located in Anchorage, has responded by developing an innovative program that includes on-campus studies about rural and remote teaching and multicultural issues, and complements this course with a practicum experience in remote rural Alaskan school districts for its pre-service elementary/middle teacher education students. Additionally, Alaska Pacific University has been able to secure additional funding for the remote practicum and thus minimize those financial hardship issues raised by Ralph (2002) and Yarrow, Ballantyre, Hansford, Herschell and Millwater (1998).

This practicum experience is called the Remote Rural Practicum program and the data from students' participation in the program is the focus of this paper.

\section{The Remote Rural Practicum Program}

As part of the pre-service elementary program at Alaska Pacific University, students enrolled in the MAT program and enrolled in the BA TTP program are offered the opportunity to participate in the remote rural practicum program.

The goals and objectives of the Remote Rural Practicum program are to:

- $\quad$ Experience teaching and learning in a rural Alaskan school;

- $\quad$ Experience rural community living and activities;

- $\quad$ Prepare and teach a unit of instruction in a $\mathrm{K}-8$ classroom in collaboration with the host teacher's assistance; and,
- $\quad$ Prepare and facilitate a community event to showcase student learning.

One of the implicit goals of the Remote Rural Practicum program is designed to encourage pre-service teachers to consider applying for a rural Alaskan teaching appointment.

The Remote Rural Practicum program consists of a five or six day experience during which the pre-service students are placed in one rural Alaskan village school. Pre-service teachers were placed at each of three participating schools for a five-day period. The three participating schools were K-12 schools with student populations ranging from 220 in Togiak to 142 in Manokotak. Additionally a faculty member from the university accompanied each group of pre-service teachers to their assigned school.

From the literature, some of the potential benefits for the participating pre-service teachers included:

- $\quad$ Provide an opportunity for students to informally meet with teachers in remote areas, and to look at the realities of living and teaching in these areas;

- $\quad$ Offer pre-service teachers from the city and large regional centers a hands-on introduction to rural schools;

- $\quad$ Provide first hand opportunities to talk to rural based teachers about rural life;

- $\quad$ Provide opportunities to establish and build networks with teachers working within specific fields of expertise;

- $\quad$ Prepare pre-service teachers for the future by broadening their career prospects; and, Enhance the pre-service teachers' skill levels to respond to the challenge of providing a broad range of educational choices in a culturally rich society. (Boylan, 2005; Munsch \& Boylan 2005; NSWDET, 2001)

A similar program, called the Beyond the Line program, has operated in New South Wales between the NSW Department of Education and Training and universities within New South Wales, including Charles Sturt University (NSW DET, 2001). The Beyond the Line program is conducted over a five-day period and like Alaska Pacific University's Remote Rural Practicum program is designed to encourage pre-service teachers to apply for rural teaching appointments (Boylan \& Wallace, 2002). The aim of this program is to:

Provide a unique experience offering you new opportunities and broadening your career knowledge of rural areas in New South Wales. 


\section{Purpose of the Study}

This study sought to evaluate the impact of the Remote Rural Practicum on APU students' views and values about teaching in remote, rural Alaska. The origins of this program can be traced back to 1995 and represent a significant commitment by Alaska Pacific University to expose its pre-service teachers to teaching and learning in remote places. The goals and objectives of the Remote Rural Practicum have been described earlier in this article.

\section{The Participants and Setting}

During April 2005, 14 pre-service teachers from Alaska Pacific University traveled to three schools located in the Southwest Region School District for the Remote Rural Practicum program accompanied by three professors from Alaska Pacific University and one from Charles Sturt University in Wagga Wagga, New South Wales, Australia. Eleven of the pre-service teachers were female (4 TPP and 7 MAT) while three were male (1 TPP and 2 MAT). These pre-service teachers lived in the schools or teacherage facilities during their five-day stay. Each was assigned a host teacher and classroom for the duration.

Self-report questionnaires were administered to the group before and immediately after their participation in the Remote Rural Practicum program. Student biographical details as well as information about why the students chose to participate in the Remote Rural Practicum program and their perceptions about rural teaching were gathered through the questionnaires. This paper reports the responses to openended questions that were comparatively analyzed from the pre and post experience questionnaires with categorical descriptors generated to identify emergent patterns in the pre-service teachers' responses.

The Southwest Region School District operates nine schools and employs 64 teachers to teach the 719 students attending these schools. The student/teacher ratio is 11.30 . Ninety-nine and six tenths percent of students are Alaska Native students. The 2001 expenditure per student was $\$ 13,676$. The three villages visited were Togiak, New Stuyahok, and Manokotak and ranged in population from 399 to 809 (Community Database Online, 2003a, 2003b, 2003c).

\section{Questionnaire Results}

Thirteen of the 14 pre-service teachers returned the post experience questionnaire. The initial biographical information did not change from pre to post questionnaire, other than one less response was gathered on the post questionnaire. The following table shows the biographical information gathered (Table 1) followed by the reasons reported for becoming part of the Remote Rural Practicum Program.

Table 1

Pre-experience Biographical Information

\section{Biographical information}

Did you grow up in a rural or remote place?

Have you lived in rural areas before the university?

Have you completed a rural or remote practicum?

Gender

\begin{tabular}{|c|c|c|}
\hline \multicolumn{2}{|c|}{ Response } & \multirow[b]{2}{*}{ If Yes, where? } \\
\hline No & $\underline{\text { Yes }}$ & \\
\hline \multirow[t]{5}{*}{$\overline{11}$} & 3 & Rural Alaska (2) \\
\hline & & Non USA (1) \\
\hline & 6 & Rural Alaska (2) \\
\hline & & Rural USA (2) \\
\hline & & Non USA (2) \\
\hline 12 & 2 & Peace Corps \\
\hline & & No details \\
\hline Male & Female & \\
\hline$\overline{3}$ & 11 & \\
\hline
\end{tabular}

One significant finding for these students was that 12 of the 14 students (85\%) reported that they had not participated in a rural practice teaching experience prior to their participation in the Remote Rural Practicum program at Alaska Pacific University. This lack of prior rural teaching experience is comparable to that reported in the earlier research by Sharplin (2002) and Boylan and Wallace (2002).
From the pre-experience questionnaire, the following open-ended question asked students: 'Why did you participate in the Remote Rural Practicum program?' Twenty-three responses were categorized by the authors to reflect general themes.

Participants stated the primary reasons for participation in the Remote Rural Practicum program being centered on gaining school and community related experiences in rural 
and remote Alaskan native villages (11 responses), e.g. 'It will be very important for a pre-service teacher to experience rural life since some of the students we will be teaching will be from rural Alaska' (Female, MAT); '...an important experience for any Alaskan teacher' (Male, $\mathrm{MAT}$ ); and 'For the experience, teaching in a small community' (Female, TPP). This was followed by a statement focusing on meeting all course requirements for graduation (7 responses) e.g. 'One: Because it's required. Two: Because I think it will be a fun learning experience' (Female MAT).

In the post experience questionnaire, the pre-service teachers were asked: "What were the highlights of the Rural Practicum Experience?" From the 25 responses recorded, 11 pre-service teachers stated that teaching and working with students in classrooms were the highlights of their experience. Lock (2007) reported that 90\% of the students in the STREP experience similarly identified important outcomes from their participation that focused on the development of a better understanding about the realities of rural teaching and attributes of rural students. Seven preservice teachers commented that living in a village for a week and being able to interact with community members were the highlights. A female MAT candidate reported: "I stayed with two wonderful teachers. WARM (sic), welcoming and terrific teachers in every way. I also connected with the children, two local women, and their families, and some elders." Another comment reflects the value of being in the village: "Getting to know real people at a real rural school, instead of reading about the school in a handout" (Male MAT).

The pre-service teachers were asked this same question prior to and after the Remote Rural Practicum experience: "What do you expect / did you learn about teaching in rural schools from the Rural Practicum Experience?" Preexperience perceptions of the challenges associated with teaching in a remote native Alaskan village were sought and recorded (Table 2). Because of, and sometimes in spite of various media representations of what is available throughout the state, and about what is happening in rural areas, the participants provided a diverse set of responses to this question.

Table 2

Challenges with Classroom Teaching in a Rural Village

\section{Category}

Teaching related problems

Adjustment to rural life

Community related problems $\underline{\text { Examples }}$

Lack of supplies/resources

Student motivation and attendance

Lack of teacher networks and professional development

Parent/teacher/student relationship building

Isolation from family and friends

Racial/cultural biases

Boredom/loneliness

Lack of facilities

Community support (especially elders)

Substance abuse

Rural peoples' attitudes

No privacy
Frequency

8

5

3

3

4

2

2

1

2

1

1

1
As perceived by pre-service teachers, the major challenge for a classroom teacher was related to being an effective and professional teacher. Examples of comments provided included: 'The teachers may not have many resources or exchanges of ideas for new lessons. It's a small very place no privacy. Relationships are very important because students and families are in contact with you or your neighbor. Limited outside resources.' (Female, MAT) and 'Resources/materials (expensive to ship books and so on). As a non-native teacher I would be concerned about connections with students, parents and community. Being far away from friends and family.' (Female, TPP). A similar range of preconceptions and challenges was identified by Sharplin (2002), with the lack of resources perceived to be the main challenge. Lock's (2007) study reported that following their STREP experience, his participants had developed a better understanding about the level of resources available in the rural schools which helped to refute their stereotyped pre-conceived images. 
As evidenced in the post experience comments, preservice teachers were more focused on classroom activities, relating their responses to pedagogy and classroom environment, rather than resources and contextualizing learning (Table 3).

Table 3

What was Learned about Classroom Teaching in a Rural Village

\begin{tabular}{lll} 
Category & Examples & Frequency \\
\cline { 2 - 2 } Teaching related discoveries & Attempts are made to meet all learner needs & 4 \\
& Teacher-centered classrooms & 2 \\
& Limited art supplies/experiences & 1 \\
& & 1 \\
Cultural/Contextual comments & Hands-on activities & 5 \\
& Relate teaching to community and culture & 2 \\
& More time/patience needed & 2 \\
& Small class sizes & 1 \\
& Elder involvement & 2 \\
Other comments & Similar problems in urban schools & 1 \\
& Limited supplies & 1 \\
\hline
\end{tabular}

A female MAT candidate commented: 'Students nearly worship the ground you walk on so it is important to be above reproach. Also the children didn't respond to questions the same way as kids in the city.' A male MAT candidate's response was: 'Many things are beyond the teacher's control. The culture can be very different from small schools outside.' Another male MAT candidate wrote: 'I was able to see how important visual instruction is. Also, verbal communication.' A female MAT candidate summed up the importance she perceived of the teacher in the rural classroom: 'The teachers really make or break the classrooms.' As reported by Nordhoff and Kleinfeld (1993) in Sleeter (2001), when pre-service teachers in the Teachers for Alaska program were immersed in practice teaching in Alaskan villages, they were more inclined to engage students in learning by using culturally relevant knowledge, rather than by telling students what they should know. One can see that a similar transformation was experienced by APU pre-service teachers in their practicum, 12 years later.

Isolation emerged as a major concern in both the pre and post experience questionnaires when the pre-service teachers were asked: 'What do you consider to be the major problems in living in rural areas?' Isolation, loneliness and alcohol were mentioned as major problems by most of the respondents after the experience by pre-service teachers. For seven of the 13 respondents isolation, was mentioned in one form or another: 'Isolated communities have no access to land transportation, except by plane.' (Female MAT); 'I have no friends or relatives there and none of mine would ever come to see me there. "Isolation" would be the word, I guess.' (Female MAT); 'For me, being a gussok (sic), it means isolation.' (Male MAT) One female in the TPP mentioned the lack of privacy: 'Everyone is in each other's business.' Alcohol or substance abuse was listed by five of the 13 respondents. One male MAT candidate commented on the need to assure community acceptance: 'Immersing and being accepted into the village culture. This takes commitment and years.'

Table 4 shows how the responses made by pre-service teachers prior to and following the experience to the question: 'What do you consider to be the major problems facing classroom teachers in rural areas?' compare. The first frequency reported is for the pre experience questionnaire while the second represents post experience responses. 
Table 4

Major Problems Facing Teachers in Rural Schools

Category
Teaching related problems

Adjustment to rural life

Community related problems
Examples and Comparisons

$\underline{\text { Pre }} \quad \underline{\text { Post }}$

Lack of supplies/resources

Student motivation and attendance

Lack of teacher networks and professional development

Parent/teacher relationship building

Assessment

Isolation from family and friends

Racial/cultural biases

Boredom/loneliness

Lack of facilities

Community support (especially elders)

Substance abuse

Rural peoples' attitudes

No privacy

Poverty/poor home life for students
$8 \quad 3$

$3 \quad 3$

13

$3 \quad 8$

04

3

23

$2 \quad 1$

10

0

$1 \quad 1$

10

$1 \quad 0$

$0 \quad 3$
From Table 4 it is clear that there has been a shift in the pre-service teachers' views about teaching related problems from a focus on physical resources to interpersonal relationships with parents, community and students. Several respondents recognized the importance of the family and community conditions in terms of success in the classroom. Two mentioned a lack of support from administrators, often in connection with behavior and discipline problems. One female MAT candidate summed up her concerns that reflect several categories in Table 4, 'Respect from some students; getting certain supplies; having a wide range of levels in one class; and behavior.' Isolation concerns did not change when comparing pre and post experience responses.

When asked to specify the changes in their impressions about rural teaching following the completion of the Remote Rural Practicum experience, pre-service teachers discussed teaching issues, cultural issues and lifestyle impressions. Having talked with, taught with and lived with teachers in the villages, 6 of the 13 respondents alluded to teacher burnout and lack of retention. 'Most of the teachers are $1^{\text {st }}$ year and don't stay.' (Female TPP) 'A teacher has to immerse in the culture and should love rural life in order to be happy.' (Female MAT) '. . . Which occurred first? Teacher burnout or student burnout?' (Male MAT). 'I have a better idea of what it would be like. From talking to the rural teachers, I learned that it can get a little depressinghigh burnout rate.' (Female MAT). Five of the 13 preservice teachers reported that they had developed a deeper appreciation and understanding of the cultural issues associated with teaching in Native Alaskan villages. 'I have learned that to teach in the rural and isolated village (one) needs dedication and understanding of the rural native culture and existence.' (Female MAT). Four pre-service teachers indicated that they would now be prepared to seek remote teaching appointments. One female (MAT) stated: 'In the community I visited I felt completely accepted. Now I could possibly see myself teaching in a village community.'

In the post experience questionnaire, pre-service teachers were asked to respond to a series of statements about their participation in the remote rural practicum, using a Likert scale with response options ranging from "Strongly Agree” to "Strongly Disagree.” All 13 pre-service teachers affirmed that they had a better understanding of the challenges facing a teacher working and living in a Native Alaskan (monocultural) setting. Eleven of the 13 pre-service teachers reported that they enjoyed the remote rural experience with 11 students indicating that they believed all APU teacher education students should participate in the Remote Rural Practicum. Additionally, 11 pre-service teachers reported that as a direct result of their participation in the program, they had developed a better understanding of the challenges that rural Native Alaskan students face when they relocate to large urban schools in Anchorage. The statement "I look forward to working in rural communities" showed six respondents agreeing to some extent and seven respondents undecided or disagreeing. 
When perusing the results, it appears that the purposes of the experience were realized and that participants gained insights into rural schools, their students and teaching in those schools. The majority of pre-service teachers reported that their participation in the Remote Rural Practicum program was beneficial and that they would recommend the program to other students at Alaska Pacific University. Lock (2007) reported that, through participation in the STREP experience, $90 \%$ of the pre-service teachers had changed their understanding about rural teaching and living. Similar changes in perceptions were reported by Todd and Agnello (2006) after pre-service teachers in a social studies class spent time working in a rural community.

\section{Implications}

Training teachers for rural placements is not the sole purpose of the APU Remote Rural Practicum experience. In order to prepare pre-service teachers more comprehensively for rural teaching, a semester-long, on-campus class coupled with an extended practicum experience (student teaching) would be more fitting and certainly beneficial to the preservice teacher (Boylan, 2005, Smith-Davis, 1989). However, through the Remote Rural Practicum program and drawing on results from other similar programs (e.g. Boylan \& Wallace, 2002; Lock, 2007), the 5-6 day intensive immersion experience can benefit rural schools, rural communities, rural teachers and pre-service teachers in several ways.

In the post experience questionnaire, pre-service teachers were asked: 'How have the courses at APU changed your attitude towards living in rural areas?' This question sought to establish whether a conceptual and contextual relationship between the academic courses offered at APU in 'Multicultural Education' and 'Alaska History' and this intensive week-long remote practicum experience had developed. Responses to this question revealed that for 6 of the 13 pre-service teachers, an overall positive linking of theory and practice had occurred while 6 pre-service teachers reported either no impact or linking of theory and practice on their views about rural teaching and 1 preservice teacher chose not to answer this question. One female TTP respondent stated that the positive changes in understandings and attitudes were not a result of the courses, but "... the village itself." One female pre-service teacher reported described this linking of theory and practice this way: 'I was able to have a real and meaningful experience because of the background (knowledge) that I've learned from APU' (Female, MAT). A male MAT candidate reported: 'It's been a positive experience for me. Although I did have some prior inclination to teach in a rural area, that inclination is now reinforced.' One female pre-service teacher reported no change in her attitudes this way: 'They haven't really. I have always loved rural Alaska.' (Female TTP). It is apparent in these responses that for almost half of the pre-service teachers the experience of living in a rural area has forged links in a more pronounced manner so that the practical aspects of cultural awareness and empathy for those living in villages were closely related to their theory based APU courses.

Pre-service teachers who completed the Remote Rural Practicum program indicated that they do have a better understanding of and empathy for rural students, especially when those students transfer to the large Alaskan urban centers and become part of urban classrooms. This assertion is supported by research by Boylan and Wallace (2002) and Lock (2007). Unlike the Sharplin (2002) study, which explored preconceived ideas about rural teaching held by pre-service teachers who had not undertaken a rural practicum, the present study has mapped positive changes in knowledge and understanding about rural schools and their communities as a result of engaging in a rural practice teaching experience. Having the opportunity to be 'in charge' of creating, delivering and assessing lessons prior to their major student teaching endeavor, these rural practicum participants developed a sense of accomplishment and feel better prepared for the experiences that are to follow. Their self-efficacy for teaching may be improved after having endured the remoteness of an Alaskan village and having successfully interacted with total strangers to become an integral part of their community for a short time. As stated in conversations with teachers and principals from participating the rural schools, the opportunity to interact with the pre-service teachers afforded a number of benefits including: 1) being valued as professionals; 2) experiencing a new learning role as cooperating/supervising teachers; 3) being allowed an opportunity to exchange new ideas and teaching approaches; and, 4) evaluating the range of different and new resources used by the pre-service teachers in their classrooms. For the entire remote learning community, the opportunity to visit their school and to meet the pre-service teachers who were teaching their children and examine the week's learning activities was well supported and valued.

Even though this study reports changes in the perceptions by only 13 pre-service teachers, in order to answer the question, "Can a week make a difference?" one needs only to look at the responses to post experience questionnaire to understand that change has occurred. For the authors, having lived and worked with these individuals before and during the experience, we did sense many changes in the pre-service teachers' levels of anticipation, then their concerns for reaching their students and finally, their feelings of success when community members shared the learning that had occurred during the short time they spent in the villages. A week can start the change process for pre-service teachers unaware of the opportunities and dilemmas facing those who choose to teach in rural, remote locations. This notion is supported by Ference and Bell (2004) who state that even though a short-term cultural immersion experience may not completely change pre- 
service teachers' attitudes and dispositions regarding other cultures, it can certainly “jumpstart” the process (p. 349).

This preliminary study has raised new questions and challenges for the authors. Researching the long-term effects of rural practicum experiences by questioning teachers who were participants in the Alaska Pacific University Remote Rural Practicum program and those involved in the Australian Beyond the Line program over the last ten years can provide additional support for this study's initial implications, that even a week spent immersed in a rural cultural practicum experience can make a difference in teacher perceptions and attitudes regarding rural teaching. We trust that this approach to immersing pre-service teachers in rural settings, no matter where they are being trained, will be considered an important addition to teacher preparation programs everywhere.

Two of the best closing comments submitted by participants sum up their experiences and give perspective to the value of the Remote Rural Practicum program.

Thank you so much for an incredible experience!! Participating in the Rural Practicum has given me a lot of insight into the challenges that occur for students and teachers when a child comes to town for school. (Female, TPP)

There is a need of Alaska Native teachers who can be role models for students in the village. If a teacher should teach in rural/remote Alaska, he/she should have a "heart" to stay there and help kids learn (and not just for money or salary.) (Female, MAT)

As stated by Christine Sleeter (2001) in her review of community-based cross-cultural immersion experiences for pre-service teachers, “Community-based cross-cultural immersion experiences seem to transform pre-service students and ground them in contextually relevant knowledge” (p. 217).

\section{References}

Alaska Teacher Placement. (2006). Retrieved on May 17, 2006 from http://alaskateacher.org/teaching_alaska.html

Allen, M.P. (2003). Eight questions on teacher preparation: What does the research say? Education Commission of the States: Denver, CO.

Australian Education Union (AEU) (2001) A national teacher shortage: A solution from the Australian Education Union. Author: Canberra, ACT.

Boylan, C. R. (2005, October). Designing a course in rural education. Paper presented at $21^{\text {st }}$ National Society for the Provision of Education in Rural Australia Conference, Darwin, NWT.
Boylan, C. R., \& Hemmings, B. (1992). Lessons for the Future: A Remote Rural Practice Teaching Program. Education in Rural Australia. 2(2), 25-32.

Boylan, C., Squires, D., \& Smith, A. (1994). Audiographic teleteaching in pre-service teacher education. Education in Rural Australia. 4(2), 23-28.

Boylan, C.R., \& Wallace, A.R. (2002, October). Beyond the Line: Promoting country schools. Paper presented at the 18th Annual National Society for the Provision of Education in Rural Australia Conference. Hahndorf, SA.

Collins, T. (1999). Attracting and retaining teachers in rural areas. (ERIC Digest No. ED 438 152)

Community Database Online (2003a). Manokotak. Retrieved on July 4, 2005 from http://www.commerce.state.ak.us/dca/commdb/CF_BL OCK.cfm

Community Database Online (2003b). New Stuyahok. Retrieved on July 4, 2005 from http://www.commerce.state.ak.us/dca/commdb/CF_BL OCK.cfm

Community Database Online (2003c). Togiak. Retrieved on July 4, 2005 from

http://www.commerce.state.ak.us/dca/commdb/CF_BL OCK.cfm

Ference, R.A., \& Bell, S. (2004). A cross-cultural immersion in the U.S.: Changing preservice teacher attitudes toward Latino ESOL students. Equity \& Excellence in Education, 37: 343-350.

Gibson, I. (1994). Policy, practice and need in the professional preparation of teachers for rural teaching. Journal of Research in Rural Education. 10(1), 68-77.

Halsey, J. (2005). Rural teacher education forum mapping of pre-service country teaching programs. Paper presented at 21st National Conference of the Society for the Provision of Education in Rural Australia, October 1-3, Darwin, Northern Territory.

Hardy, L. (1998). A good teacher is hard to find. American School Board Journal. 185(9), 20-23.

Human Rights and Equal Opportunity Commission (HREOC) (2000). Emerging Themes. Report of the National Inquiry into Rural and Remote Education. Author: Sydney.

Jimerson, L. (2005, September). Making it worse: How No Child Left Behind magnifies challenges of recruiting and retaining qualified teachers in high poverty rural schools. Paper prepared for the Center of Educational Policy, Washington, D.C.

Jordan, T.S., \& Jordan, K.F. (2004). Rural schools under scrutiny. The Rural Educator, 26(1), 1-4.

Kirby, S.N., Berends, M. \& Naftel, S. (1999). Supply and demand of minority teachers in Texas: Problems and Prospects. Education Evaluation and Policy Analysis, 21(1), 47-66. 
Lemke, J.C., \& Harrison, S. (2002). Maintaining quality in an era of teacher shortages. The Rural Educator, 24(2), 8-11.

Lock, G. (2007). The effectiveness of student teacher rural experience program in preparing graduate teachers for rural appointments. Paper presented at $23^{\text {rd }}$ National Conference of the Society for the Provision of Education in Rural Australia, Perth, Western Australia.

Lowe, J. M. (2006). Rural education: Attracting and recruiting teachers in small schools. The Rural Educator, 27(2), 28-32.

Munsch, T.R., \& Boylan, C.R. (2005). Teaching in remote Alaskan schools: The Remote Rural Practicum program. Paper presented at 21st National Rural Education Conference, Society for the Provision of Education in Rural Australia, Darwin, NT.

Murphy, P., \& Cross, W. (1990). Preparing teachers for rural schools: A Canadian approach. The Rural Educator, 11(3), 10-11.

Nichols, J. (2004). Recruiting and interviewing teachers in rural school districts: Protocol or potluck? The Rural Educator, 26(1), 40-47.

Nordhoff, K., \& Kleinfeld, J. (1993). Preparing teachers for multicultural classrooms. Teaching and Teacher Education, 9, 27-39.

New South Wales Department of Education and Training. (2001). Beyond The Line. Author: Bathurst.

Northwest Regional Education Laboratory. (1999). Characteristics of small, rural schools. Retrieved May 17, 2006 from http://www.nwrel.org/ruraled/profiles.html

Ralph, E.G. (2002). Teaching in rural schools: A synthesis of interns and cooperating teachers' views. The Rural Educator, 24(2), 13-22.
Sharplin, E. (2002). Rural retreat or outback hell: Expectations of rural and remote teaching. Issues in Educational Research. 12(1), 49-63.

Sleeter, C.E. (2001). Epistemological diversity in research on pre-service teacher preparation for historically underserved children. In Review of Research in Education, Vol. 25, 2000-2001. Walter G. Secada, (ed.), 209-250. American Educational Research Association: Washington, DC.

Smith-Davis, J. (1989). Recruiting and retaining special educators in rural areas: Strategies from the field. Educational Considerations, 17(1), 33-35.

State of Alaska. (ND). AS 14.43.600-14.43.700. Retrieved May 17, 2006 from http://www.legis.state.ak.us/cgibin/folioisa.dll/stattx05/query=definition+of+rural/doc/ \{@6567\}?

Todd, R.H., \& Agnello, M.F. (2006). Looking at rural communities in teacher preparation: Insight into a P-12 schoolhouse. Social Studies, 97(4), 178-184.

United States Census Bureau (2000). State and county quick facts, Alaska. Retrieved on June 27, 2005 from http://quickfacts.census.gov/qfd/states/02000.html

Williams, C. (2002, February). Feet on the ground and running. Paper presented at Challenging Futures Conference, University of New England, Armidale, NSW.

Yarrow, A., Ballantyre, R., Hansford, B., Herschell, P., \& Millwater, J. (1998). Teacher/intern partnerships in isolated areas: A project overview. Education in Rural Australia, 8(1), 29-31.

Yarrow, A., Herschell, P., \& Millwater, J. (1999). Listening to Country Voices: Attracting and retaining teachers for rural and remote areas. Education in Rural Australia, 9(2), 1-12. 